\title{
TEORES DE Fe, Mn, Zn, Cu, Ni E Co EM SOLOS DE REFERÊNCIA DE PERNAMBUCO ${ }^{(1)}$
}

\author{
Caroline Miranda Biondi ${ }^{(2)}$, Clístenes Williams Araújo do \\ Nascimento ${ }^{(3)}$, Adelazil de Brito Fabricio Neta ${ }^{(4)}$ \& Mateus Rosas \\ Ribeiro $^{(3)}$
}

\section{RESUMO}

Metais pesados formam um grupo de elementos com particularidades relevantes e de ocorrência natural no ambiente, como elementos acessórios na constituição de rochas. Esses elementos, apesar de associados à toxidez, exigem tratamento diferenciado em relação aos xenobióticos, uma vez que diversos metais possuem essencialidade ( $\mathrm{Fe}, \mathrm{Mn}, \mathrm{Cu}, \mathrm{Zn}$ e $\mathrm{Ni}$ ) e benefício (Co) comprovados para as plantas. Nesse contexto, o objetivo deste trabalho foi determinar os teores naturais dos metais Fe, Mn, Zn, Ni, Cu e Co nos solos de referência de Pernambuco. Foram coletadas amostras de solo nas três regiões fisiográficas (Zona da Mata, Agreste e Sertão), dos dois primeiros horizontes dos 35 solos de referência do Estado de Pernambuco. A digestão das amostras baseou-se no método 3051A (USEPA, 1998), e a determinação foi efetuada em ICP-OES. Correlações significativas foram estabelecidas entre os metais e entre estes e a fração argila do solo, em ambos os horizontes, indicando a associação comum da maioria dos metais com solos mais argilosos. A maioria dos solos apresentou teores de Fe, Mn, $\mathrm{Zn}, \mathrm{Cu}, \mathrm{Ni}$ e Co menores que os de solos de outras regiões do País, com litologia mais máfica, o que corrobora o fato de que os teores desses elementos são mais diretamente relacionados aos minerais Fe-magnesianos. Os resultados indicam baixo potencial dos solos de Pernambuco em liberar $\mathrm{Cu}$, Co e Ni para plantas, enquanto deficiências de $\mathrm{Zn}, \mathrm{Fe}$ e Mn são menos prováveis. Os teores naturais de $\mathrm{Fe}, \mathrm{Mn}, \mathrm{Zn}, \mathrm{Cu}, \mathrm{Ni}$ e $\mathrm{Co}$ determinados podem ser utilizados como base para definição dos Valores de Referência de Qualidade para os solos de Pernambuco, de acordo com o preconizado pela legislação nacional.

Termos de indexação: metais pesados, elementos-traço, contaminação do solo, micronutrientes.

\footnotetext{
(1) Parte da Tese de Doutorado da primeira autora apresentada ao Programa de Pós-Graduação em Ciência do Solo, Universidade Federal Rural de Pernambuco - UFRPE. Recebido para publicação em abril de 2010 e aprovado em março de 2011.

(2) Professora Adjunta do Departamento de Agronomia, Universidade Federal Rural de Pernambuco - UFRPE. R. Dom Manoel de Medeiros s/n, Dois Irmãos, CEP 52171-900 Recife (PE). Bolsista do CNPq. E-mail: carolinebiondi@yahoo.com

(3) Professor Associado do Departamento de Agronomia, UFRPE. Bolsista do CNPq. E-mails: clistenes@depa.ufrpe.br; mrosas@depa.ufrpe.br

(4) Mestranda do Programa de Pós-Graduação em Ciência do Solo, UFRPE. E-mail: adelazil_ufrpe@yahoo.com.br
} 


\title{
SUMMARY: CONCENTRATIONS OF Fe, Mn, Zn, Cu, Ni AND Co IN BENCHMARK SOILS OF PERNAMBUCO, BRAZIL
}

\begin{abstract}
Heavy metals are a group of elements with specific features and natural occurrence in the environment, representing an accessory in the formation of rocks. These elements, although associated with toxicity, must be treated different from xenobiotics, since many metals are evidentially essentials ( $\mathrm{Fe}, \mathrm{Mn}, \mathrm{Cu}, \mathrm{Zn}$, and $\mathrm{Ni}$ ) and beneficial (Co) for plants. In this context, the objective was to determine the natural contents of the metals iron ( $\mathrm{Fe})$, manganese (Mn), zinc ( $\mathrm{Zn}$ ), nickel (Ni), copper (Cu) and cobalt (Co) in benchmark soils of Pernambuco. Soil samples were collected in the three physiographic regions of the state (Zona da Mata, Agreste and Sertão), in the first two horizons of the 35 benchmark soils of the state of Pernambuco. Sample digestion was based on the method 3051A (USEPA, 1998) and determined by ICPOES. Significant correlations were found between these metals and those with the clay soil fraction in both horizons, indicating the general association of most metals to the most clayey soils. The $\mathrm{Fe}, \mathrm{Mn}, \mathrm{Zn}, \mathrm{Cu}, \mathrm{Ni}$, and Co contents of most soils were lower than in soils from other regions of the country and more mafic lithology, which confirms that the contents of these elements are more directly related to iron-magnesium minerals. The results indicate a low capacity of the soils of Pernambuco to release $\mathrm{Cu}$, Co and Ni to plants, while deficiencies of $\mathrm{Zn}$, $\mathrm{Fe}$ and $\mathrm{Mn}$ are less likely. The natural contents of $\mathrm{Fe}, \mathrm{Mn}, \mathrm{Zn}, \mathrm{Cu}, \mathrm{Ni}$, and Co determined here can be used as a basis for defining the Quality Reference Values for soils of Pernambuco, as stipulated by the Brazilian legislation.
\end{abstract}

Index terms: heavy metals, trace elements, soil contamination, micronutrients.

\section{INTRODUÇÃO}

Metais pesados formam um grupo de elementos com particularidades relevantes e de ocorrência natural no ambiente, como elementos acessórios na constituição de rochas. Esses elementos, apesar de associados à toxidez, exigem tratamento diferencial em relação aos xenobióticos, uma vez que diversos metais possuem essencialidade ( $\mathrm{Fe}, \mathrm{Mn}, \mathrm{Ni}$, $\mathrm{Cu}$ e $\mathrm{Zn}$ ) e beneficio (Co) comprovado para plantas. Nesses casos, o conhecimento de seus teores naturais tornase duplamente relevante, uma vez que possibilita definir valores orientadores de qualidade do solo, com a geração de valores de referência de qualidade, a serem aplicados em atividades de monitoramento e, por outro lado, possibilita avaliar o potencial do solo em suprir de elementos importantes ao metabolismo vegetal, a médio e longo prazo.

Teores naturais de metais dependem da composição do material de origem, dos processos pedogenéticos e do grau de desenvolvimento dos solos - características essas específicas para cada ambiente, o que torna inadequada a extrapolação desses valores para países e áreas diferentes do local de obtenção dos dados. A determinação dos teores naturais é o primeiro passo para a definição de valores orientadores de situações de contaminação, essencial para a construção de uma legislação voltada para o monitoramento e a intervenção legal condizentes com a realidade local, evitando intervenções inadequadas que incorram em prejuízos financeiros e sociais (Baize \& Sterckeman, 2001). No Brasil, recentemente (CONAMA, 2009) foi estabelecida uma legislação nacional sobre teores permissíveis de metais em solos que reconhece a importância das diferenças regionais quanto a esses teores.

Uma das formas de avaliação dos teores naturais e da variabilidade dos teores de metais em uma região é pela utilização de classes de solo representativas da região, como, por exemplo, quando se dispõe de um banco de solos de referência: conjunto de solos com representativa extensão, podendo o conhecimento de suas propriedades e comportamento ser aplicado para compreensão e interpretação de solos com propriedades semelhantes (USDA, 2010). Os critérios utilizados no estabelecimento de solos de referência também são ideais para a determinação de valores orientadores de qualidade do solo, corroborando a recomendação do CONAMA (2009) em sua resolução 420/2009, anexo I, relativa ao estabelecimento de critérios e valores orientadores referentes à presença de substâncias químicas, para a proteção da qualidade do solo.

Nesse contexto, o objetivo deste trabalho foi determinar os teores naturais dos metais $\mathrm{Fe}, \mathrm{Mn}, \mathrm{Zn}$, $\mathrm{Ni}, \mathrm{Cu}$ e Co nos solos de referência de Pernambuco. Os resultados deste trabalho permitirão o estabelecimento de valores de referência de qualidade desses elementos para solos do Estado de Pernambuco, além de poderem ser utilizados para inferências sobre a possibilidade de deficiências de micronutrientes $(\mathrm{Fe}$, $\mathrm{Mn}, \mathrm{Zn}, \mathrm{Cu}$ e Ni) nesses solos.

\section{MATERIAL E MÉTODOS}

Para o desenvolvimento do trabalho, foram coletadas amostras de solo, nas três regiões 
fisiográficas (Zona da Mata, Agreste e Sertão), dos dois primeiros horizontes dos 35 solos de referência do Estado de Pernambuco. Localização e características químicas e físicas desses solos, bem como informações compiladas de pesquisas realizadas anteriormente (Ribeiro et al., 1999; Oliveira \& Nascimento, 2006), encontram-se nos quadros 1 e 2 . As amostras, após secas ao ar, foram passadas em peneiras de náilon com abertura de $2 \mathrm{~mm}$. Alíquota desse material foi macerada em almofariz de ágata e passada em peneiras de $0,3 \mathrm{~mm}$ de abertura $\left(\mathrm{ABNT}^{\circ}{ }^{\circ} 50\right)$, com malha de aço inoxidável, visando evitar contaminações.
A digestão das amostras baseou-se no método 3051A (USEPA, 1998). O conjunto solo-tubo digestor foi mantido em sistema fechado, forno de micro-ondas (Mars Xpress), por $8 \mathrm{~min}$ e $40 \mathrm{seg}$ na rampa de temperatura, tempo necessário para atingir $175^{\circ} \mathrm{C}$, mantendo-se essa temperatura por mais 4 min e $30 \mathrm{seg}$. Após resfriamento, as amostras foram transferidas para balões certificados (NBR ISO/IEC) de $50 \mathrm{~mL}$, sendo o volume dos balões completado com água ultrapura e os extratos filtrados em papelfiltro lento (Macherey Nagel®). As digestões foram realizadas em duplicatas.

\section{Quadro 1. Classe de solo, localização, município e região fisiográfica dos solos de referência de Pernambuco}

\begin{tabular}{|c|c|c|c|}
\hline Perfil & Classe de solo & Localização & Município \\
\hline \multicolumn{4}{|c|}{ Zona da Mata } \\
\hline 1 & Argissolo Vermelho-Amarelo distrófico húmico textura média/argilosa & $07^{\circ} 25^{\prime} 22^{\prime \prime} \mathrm{S} / 35^{\circ} 10^{\prime} 54^{\prime \prime} \mathrm{W}$ & Itambé \\
\hline 2 & Argissolo Amarelo distrófico latossólico A moderado textura arenosa/média & $07^{\circ} 37^{\prime} 30^{\prime \prime} \mathrm{S} / 34^{\circ} 57^{\prime} 30^{\prime \prime} \mathrm{W}$ & Goiana \\
\hline 3 & Espodossolo Humilúvico órtico dúrico arênico A moderado & $07^{\circ} 38^{\prime} 41^{\prime \prime} \mathrm{S} / 34^{\circ} 56^{\prime} 44^{\prime \prime} \mathrm{W}$ & Goiana \\
\hline 4 & Argissolo Vermelho-Amarelo distrófico típico A moderado textura média/argilosa & $08^{\circ} 01^{\prime} 42^{\prime \prime} \mathrm{S} / 34^{\circ} 51^{\prime} 42^{\prime \prime} \mathrm{W}$ & Moreno \\
\hline 5 & Chernossolo Argilúvico órtico típico textura média/argilosa & $07^{\circ} 44^{\prime} 32^{\prime \prime} \mathrm{S} / 35^{\circ} 14^{\prime} 04^{\prime \prime} \mathrm{W}$ & Nazaré da Mata \\
\hline 6 & Latossolo Amarelo distrocoeso típico A moderado textura argilosa & $08^{\circ} 38^{\prime} 39^{\prime \prime} \mathrm{S} / 35^{\circ} 09^{\prime} 15^{\prime \prime} \mathrm{W}$ & Rio Formoso \\
\hline 7 & Nitossolo Vermelho distroférrico típico A moderado textura muito argilosa & $08^{\circ} 18^{\prime} 00^{\prime \prime} \mathrm{S} / 34^{\circ} 59^{\prime} 00^{\prime \prime} \mathrm{W}$ & Cabo \\
\hline 8 & Argissolo Vermelho eutrófico nitossólico textura muito argilosa & $07^{\circ} 25^{\prime} 17^{\prime \prime} \mathrm{S} / 35^{\circ} 16^{\prime} 23^{\prime \prime} \mathrm{W}$ & Camutanga \\
\hline 9 & Plintossolo Argilúvico distrófico abrúptico A moderado textura média/argilosa & $07^{\circ} 37^{\prime} 30^{\prime \prime} \mathrm{S} / 34^{\circ} 57^{\prime} 30^{\prime \prime} \mathrm{W}$ & Goiana \\
\hline 10 & Argissolo Amarelo distrófico fragipânico A moderado textura média/argilosa & $07^{\circ} 36^{\prime} 20^{\prime \prime} \mathrm{S} / 35^{\circ} 08^{\prime} 43^{\prime \prime} \mathrm{W}$ & Aliança \\
\hline 11 & Organossolo Háplico hêrmico típico & $08^{\circ} 27^{\prime} 37^{\prime \prime} \mathrm{S} / 35^{\circ} 04^{\prime} 48^{\prime \prime} \mathrm{W}$ & Ipojuca \\
\hline 12 & Gleissolo Háplico Ta eutrófico típico A moderado textura argilosa & $08^{\circ} 25^{\prime} 22^{\prime \prime} \mathrm{S} / 35^{\circ} 01^{\prime} 14^{\prime \prime} \mathrm{W}$ & Ipojuca \\
\hline \multicolumn{4}{|c|}{ Agreste } \\
\hline 13 & Neossolo Regolítico distrófico típico A moderado textura média (leve) & $08^{\circ} 21^{\prime} 42^{\prime \prime} \mathrm{S} / 36^{\circ} 10^{\prime} 26^{\prime \prime} \mathrm{W}$ & São Caetano \\
\hline 14 & Planossolo Háplico eutrófico arênico solódico A moderado textura arenosa/argilosa & $08^{\circ} 21^{\prime} 28^{\prime \prime} \mathrm{S} / 36^{\circ} 10^{\prime} 20^{\prime \prime} \mathrm{W}$ & São Caetano \\
\hline 15 & Planossolo Háplico eutrófico solódico A moderado textura média (leve)/média & $08^{\circ} 27^{\prime} 26^{\prime \prime S} / 36^{\circ} 12^{\prime} 49^{\prime \prime} \mathrm{W}$ & $\begin{array}{l}\text { Cachoeirinha } \\
\text { Rio das Almas }\end{array}$ \\
\hline 16 & $\begin{array}{l}\text { Argilossolo Vermelho eutrófico Câmbico A moderado textura } \\
\text { média/argilosa cascalhenta }\end{array}$ & $08^{\circ} 10^{\prime} 21^{\prime \prime S} / 25^{\circ} 54^{\prime} 35^{\prime \prime} \mathrm{W}$ & \\
\hline 17 & Neossolo Regolítico distrófico léptico A moderado textura média (leve) cascalhenta & $08^{\circ} 13^{\prime} 54^{\prime \prime} \mathrm{S} / 35^{\circ} 55^{\prime} 15^{\prime \prime} \mathrm{W}$ & Caruaru \\
\hline 18 & $\begin{array}{l}\text { Argissolo Amarelo distrófico abrúptico plíntico A moderado textura } \\
\text { média/muito argilosa }\end{array}$ & $07^{\circ} 52^{\prime} 47^{\prime \prime S} / 31^{\circ} 55^{\prime} 18^{\prime \prime} \mathrm{W}$ & Vertentes \\
\hline 19 & Planossolo Nátrico sálico típico A fraco textura média (leve)/média & $07^{\circ} 58^{\prime} 22^{\prime \prime} \mathrm{S} / 36^{\circ} 11^{\prime} 02^{\prime \prime} \mathrm{W}$ & Jataúba \\
\hline 20 & Latossolo Vermelho-Amarelo distrófico húmico textura argilosa & $08^{\circ} 14^{\prime} 19^{\prime \prime} \mathrm{S} / 36^{\circ} 10^{\prime} 28^{\prime \prime} \mathrm{W}$ & Caruaru \\
\hline 21 & $\begin{array}{l}\text { Argissolo Vermelho-Amarelo eutrófico abrúptico espessarênico textura } \\
\text { arenosa/argilosa cascalhenta }\end{array}$ & $08^{\circ} 42^{\prime} 45^{\prime \prime} \mathrm{S} / 36^{\circ} 25^{\prime} 00^{\prime \prime} \mathrm{W}$ & Jupi \\
\hline 22 & Argissolo Amarelo distrófico abrúptico húmico textura média/muito argilosa & $09^{\circ} 03^{\prime} 00^{\prime \prime} \mathrm{S} / 36^{\circ} 29^{\prime} 00^{\prime \prime} \mathrm{W}$ & Garanhuns \\
\hline 23 & Neossolo Litólico eutrófico típico A fraco textura média substrato gnaisse & $08^{\circ} 04^{\prime} 19^{\prime \prime} \mathrm{S} / 36^{\circ} 03^{\prime} 22^{\prime \prime} \mathrm{W}$ & Caruaru \\
\hline 24 & $\begin{array}{l}\text { Sertão } \\
\text { Argissolo Amarelo eutrófico abrúptico plíntico A moderado } \\
\text { textura média (leve)/argilosa }\end{array}$ & $09^{\circ} 03^{\prime} 46^{\prime \prime} \mathrm{S} / 40^{\circ} 18^{\prime} 46^{\prime \prime} \mathrm{W}$ & Petrolina \\
\hline 25 & Planossolo Nátrico sálico típico A fraco textura média (leve)/argilosa & $09^{\circ} 02^{\prime} 30^{\prime \prime} \mathrm{S} / 40^{\circ} 15^{\prime} 07^{\prime \prime} \mathrm{W}$ & Petrolina \\
\hline 26 & Neossolo Quartzarênico órtico típico A fraco & $09^{\circ} 21^{\prime} 13^{\prime \prime} \mathrm{S} / 40^{\circ} 28^{\prime} 37^{\prime \prime} \mathrm{W}$ & Petrolina \\
\hline 27 & Neossolo Flúvico sódico sálico A moderado textura argilosa & $08^{\circ} 43^{\prime} 18^{\prime \prime} \mathrm{S} / 37^{\circ} 31^{\prime} 27^{\prime \prime} \mathrm{W}$ & Ibimirim \\
\hline 28 & Neossolo Flúvico sódico salino A moderado textura média/arenosa & $08^{\circ} 30^{\prime} 26^{\prime \prime} \mathrm{S} / 37^{\circ} 37^{\prime} 24^{\prime \prime} \mathrm{W}$ & Ibimirim \\
\hline 29 & Neossolo Quartzarênico órtico típico A fraco & $08^{\circ} 38^{\prime} 19^{\prime \prime} \mathrm{S} / 37^{\circ} 40^{\prime} 04^{\prime \prime} \mathrm{W}$ & Ibimirim \\
\hline 30 & Luvissolo Crômico órtico típico A moderado textura média cascalhenta/argilosa & $08^{\circ} 30^{\prime} 10^{\prime \prime} \mathrm{S} / 39^{\circ} 19^{\prime} 39^{\prime \prime} \mathrm{W}$ & Cabrobó \\
\hline 31 & Latossolo Amarelo distrófico argissólico A moderado textura média & $07^{\circ} 44^{\prime} 33^{\prime \prime} \mathrm{S} / 40^{\circ} 12^{\prime} 11^{\prime \prime} \mathrm{W}$ & Trindade \\
\hline 32 & $\begin{array}{l}\text { Cambissolo Háplico Tb eutrófico latossólico A moderado textura } \\
\text { argilosa }\end{array}$ & $07^{\circ} 48^{\prime} 29^{\prime \prime} \mathrm{S} / 38^{\circ} 08^{\prime} 15^{\prime \prime} \mathrm{W}$ & $\begin{array}{l}\text { Santa Cruz } \\
\text { da Baixa Verde }\end{array}$ \\
\hline 33 & Vertissolo Háplico órtico chernossólico textura argilosa & $07^{\circ} 37^{\prime} 44^{\prime \prime} \mathrm{S} / 40^{\circ} 03^{\prime} 14^{\prime \prime} \mathrm{W}$ & Bodocó \\
\hline 34 & $\begin{array}{l}\text { Argissolo Amarelo eutrófico plíntico A fraco textura média } \\
\text { (leve)/argilosa }\end{array}$ & $08^{\circ} 19^{\prime} 35^{\prime \prime} \mathrm{S} / 40^{\circ} 16^{\prime} 36^{\prime \prime} \mathrm{W}$ & $\begin{array}{l}\text { Santa Cruz da } \\
\text { Venerada }\end{array}$ \\
\hline 35 & Neossolo Litólico eutrófico típico A moderado textura média substrato xisto & $08^{\circ} 00^{\prime} 95^{\prime \prime} \mathrm{S} / 38^{\circ} 53^{\prime} 39^{\prime \prime} \mathrm{W}$ & Verdejante \\
\hline
\end{tabular}


Quadro 2. Características químicas dos horizontes superficial e subsuperficial dos solos de referência do Estado de Pernambuco

\begin{tabular}{|c|c|c|c|c|c|c|c|c|c|}
\hline Perfil & Prof. & $\mathrm{pH} \mathrm{H}_{2} \mathrm{O}$ & $\mathrm{Al}^{3+(2)}$ & $\mathrm{Ca}^{2+}+\mathrm{Mg}^{2+(2)}$ & $\mathbf{K}^{+(3)}$ & $\mathrm{Na}^{+(3)}$ & $\mathbf{P}^{(3)}$ & P-rem ${ }^{(4)}$ & $\mathrm{CO}^{(1)}$ \\
\hline & $\mathrm{cm}$ & $(1: 2,5)$ & \multicolumn{4}{|c|}{$-\mathrm{cmol}_{\mathrm{c}} \mathrm{dm}^{-3}$} & $\mathrm{mg} \mathrm{dm} \mathrm{m}^{-3}$ & $m g L^{-1}$ & $\mathrm{~g} \mathrm{~kg}^{-1}$ \\
\hline \multicolumn{10}{|c|}{ Zona da Mata } \\
\hline 1 & $0-40$ & 4,9 & 2,7 & 2,9 & 0,08 & 0,07 & 0,0 & 13,4 & 35,2 \\
\hline & $40-70$ & 4,6 & $\overline{2}, 6$ & 1,0 & 0,02 & 0,06 & 0,0 & 10,9 & 17,1 \\
\hline 2 & $0-14$ & 4,7 & 0,4 & 3,7 & 0,20 & 0,13 & 9,0 & 53,7 & 48,9 \\
\hline 2 & $14-36$ & 4,9 & 0,2 & 1,8 & 0,05 & 0,04 & 1,0 & 48,4 & 7,5 \\
\hline 3 & $0-15$ & 5,0 & 0,5 & 1,1 & 0,03 & 0,03 & 1,0 & 37,1 & 12,9 \\
\hline & $15-46$ & 5,4 & 0,3 & 0,6 & 0,02 & 0,03 & 0,0 & 53 & 6,1 \\
\hline 4 & $0-13$ & 4,7 & 2,3 & 0,9 & 0,24 & 0,12 & 7,0 & 31,7 & 27,3 \\
\hline & $13-24$ & 4,5 & 1,0 & 0,9 & 0,2 & 0,08 & 2,0 & 37,4 & 10,5 \\
\hline 5 & $0-30$ & 5,2 & 0,2 & 5,3 & 0,27 & 0,16 & 31,0 & 41,5 & 24,6 \\
\hline & $30-57$ & 5,3 & 0,1 & 6,7 & 0,08 & 0,23 & 3,0 & 38,4 & 16,0 \\
\hline 6 & $0-10$ & 5,1 & 1,6 & 0,4 & 0,10 & 0,06 & 3,0 & 27,7 & 22,4 \\
\hline & $10-30$ & 5,5 & 1,3 & 0,2 & 0,05 & 0,03 & 1,0 & 19,3 & 12,2 \\
\hline 7 & $0-14$ & 5,4 & 0,6 & 1,6 & 0,1 & 0,15 & 6,0 & 22,9 & 26,2 \\
\hline & $14-30$ & 5,4 & 1,5 & 0,9 & 0,06 & 0,07 & 1,0 & 6,5 & 14,1 \\
\hline 8 & $0-17$ & 4,8 & 0,2 & 2,7 & 0,58 & 0,07 & 3,0 & 46,0 & 16,0 \\
\hline 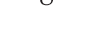 & $17-35$ & 4,6 & 0,2 & 2,4 & 0,35 & 0,07 & 1,0 & 46,1 & 11,8 \\
\hline 9 & $0-15$ & 5,1 & 0,2 & 0,7 & 0,19 & 0,09 & 6,0 & 55,5 & 10,3 \\
\hline 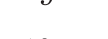 & $15-35$ & 4,9 & 0,7 & 0,3 & 0,03 & 0,04 & 2,0 & 52,2 & 5,7 \\
\hline 10 & $0-28$ & 5,7 & 0,2 & 1,5 & 0,08 & 0,05 & 38,0 & 56,6 & 7,2 \\
\hline & $28-50$ & 5,5 & 0,4 & 0,5 & 0,03 & 0,02 & 9,0 & 51,4 & $\begin{array}{r}3,0 \\
280\end{array}$ \\
\hline 11 & $0-20$ & 4,2 & 6,5 & $\begin{array}{l}10,6 \\
12,8\end{array}$ & 0,14 & 0,14 & 6,0 & 16,0 & 380,0 \\
\hline 12 & $\begin{array}{r}20-40 \\
0-20\end{array}$ & $\begin{array}{l}4,1 \\
5,8\end{array}$ & $\begin{array}{l}1,2 \\
0,2\end{array}$ & $\begin{array}{l}42,8 \\
17,0\end{array}$ & $\begin{array}{l}0,07 \\
0,17\end{array}$ & $\begin{array}{l}0,08 \\
0,04\end{array}$ & $\begin{array}{r}3,0 \\
85,0\end{array}$ & $\begin{array}{l}18,1 \\
40,7\end{array}$ & $\begin{array}{l}600,0 \\
160,0\end{array}$ \\
\hline 12 & $\begin{array}{r}0-20 \\
20-42\end{array}$ & $\begin{array}{l}5,8 \\
6,1\end{array}$ & $\begin{array}{l}0,2 \\
0,5\end{array}$ & $\begin{array}{l}17,0 \\
17,7\end{array}$ & $\begin{array}{l}0,77 \\
0,02\end{array}$ & $\begin{array}{l}0,04 \\
0,06\end{array}$ & $\begin{array}{l}85,0 \\
37,0\end{array}$ & 30,7 & $\begin{array}{l}160,0 \\
290,0\end{array}$ \\
\hline \multicolumn{10}{|c|}{ Agreste } \\
\hline 13 & $0-20$ & 5,1 & 0,3 & 1,4 & 0,34 & 0,08 & 5,0 & 60,0 & 13,2 \\
\hline & $20-\overline{58}$ & 4,7 & 0,8 & 0,4 & 0,13 & 0,06 & 4,0 & 56,8 & 7,0 \\
\hline 14 & $0-15$ & 5,5 & 0,0 & & 0,64 & 0,17 & 32,0 & & 14,0 \\
\hline & $15-48$ & 4,9 & 0,9 & 1,6 & 0,49 & 0,36 & 12,0 & 57,7 & 11,6 \\
\hline 15 & $0-11$ & 5,5 & 0,2 & 4,8 & 0,49 & 0,27 & 32,0 & 56,2 & 10,9 \\
\hline & $11-45$ & 5,3 & 0,0 & 23,6 & 0,11 & 1,19 & 17,0 & $52, \overline{5}$ & 3,1 \\
\hline 16 & $0-16$ & 5,7 & 0,2 & 1,3 & 0,22 & 0,16 & 3,0 & 31,3 & 50,0 \\
\hline & $16-35$ & 4,8 & 0,2 & 1,7 & 0,22 & 0,14 & 0,5 & 19,8 & 50,0 \\
\hline 17 & $0-15$ & 5,2 & 0,1 & 4,2 & 0,51 & 0,12 & 13,0 & 37,9 & 28,0 \\
\hline 18 & $\begin{array}{c}15-30 \\
0-9\end{array}$ & $\begin{array}{l}4,9 \\
6,1\end{array}$ & $\begin{array}{l}0,1 \\
0,0\end{array}$ & $\begin{array}{l}3,2 \\
0,9\end{array}$ & 0,33 & 0,19 & $\begin{array}{r}3,0 \\
210\end{array}$ & $\begin{array}{l}40,1 \\
36,9\end{array}$ & $\begin{array}{l}17,9 \\
124\end{array}$ \\
\hline 10 & $\begin{array}{l}0-9 \\
9-26\end{array}$ & $\begin{array}{l}6,1 \\
5,4\end{array}$ & $\begin{array}{l}0,0 \\
0,0\end{array}$ & $\begin{array}{l}0,9 \\
1,4\end{array}$ & $\begin{array}{l}0,35 \\
0,6\end{array}$ & $\begin{array}{l}0,08 \\
0,12\end{array}$ & $\begin{array}{l}21,0 \\
76,0\end{array}$ & $\begin{array}{l}36,9 \\
37,3\end{array}$ & $\begin{array}{r}12,4 \\
9,3\end{array}$ \\
\hline 19 & $0-14$ & 5,4 & 0,1 & 5,8 & 0,42 & 0,22 & 30,0 & 35,5 & 7,0 \\
\hline & $14-45$ & 7,0 & 0,1 & 11,5 & 0,04 & 2,65 & 17,0 & 35 & 4,6 \\
\hline 20 & $0-12$ & 4,2 & 2,2 & 1,7 & 0,24 & 0,07 & 5,0 & 17,1 & 40,5 \\
\hline & $12-38$ & 4,6 & 2,1 & 0,3 & 0,13 & 0,04 & 1,0 & 16,9 & 22,5 \\
\hline 21 & $0-12$ & 6,1 & 0,0 & 2,7 & 0,28 & 0,07 & 25,0 & 60,0 & 12,4 \\
\hline & $12-7 \overline{5}$ & 5,8 & 0,1 & 1 & 0,02 & 0,04 & 3,0 & 52,4 & 7,0 \\
\hline 22 & $0-15$ & 4,7 & 1,1 & 0,6 & 0,09 & 0,01 & 3,0 & 45,9 & 35,0 \\
\hline & $15-37$ & 4,4 & 1,7 & 0,4 & 0,04 & 0,01 & 2,0 & 38,4 & 22,5 \\
\hline $22 \mathrm{~A}$ & $0-6$ & 7,5 & 0,0 & 11,6 & 0,63 & 0,12 & $45 \overline{5}, 3$ & 60,0 & 40,0 \\
\hline & $6-12$ & 7,8 & 0,0 & 8,9 & 0,37 & 0,12 & 127,8 & 60 & 40,0 \\
\hline \multicolumn{10}{|c|}{ Sertão } \\
\hline 23 & $0-6$ & 6,2 & 0,1 & 3,0 & 0,42 & 0,11 & 3,0 & 57,2 & 7,7 \\
\hline & $6-18$ & 6,0 & 0,1 & 2 & 0,37 & 0,09 & 2,0 & 59 & 5,4 \\
\hline 24 & $0-15$ & 7,2 & 0,1 & 1,8 & 0,14 & 0,28 & 4,0 & 57,7 & 5,4 \\
\hline & $15-30$ & 7,5 & 0,2 & 1,3 & 0,12 & 0,17 & 3,0 & 56,6 & 3,8 \\
\hline 25 & $0-15$ & 5,5 & 0,1 & 2,0 & 0,16 & 0,04 & 9,0 & 59,0 & 12,4 \\
\hline & $15-28$ & 5,4 & 0,2 & 1,3 & 0,1 & 0,02 & 3,0 & 57,5 & 4,6 \\
\hline 26 & $0-11$ & 7,0 & 0,0 & 14,6 & 0,66 & 18,50 & 239,0 & 51,4 & 8,5 \\
\hline & $11-40$ & 7,2 & 0,0 & 18,6 & 0,42 & 23,29 & 227,0 & 50 & 3,8 \\
\hline 27 & $0-25$ & 7,9 & 0,0 & 18,2 & 1,26 & 0,97 & 102,0 & 52,6 & 8,5 \\
\hline & $25-38$ & 7,8 & 0,0 & 14,5 & 0,85 & 0,95 & 77,0 & 54,7 & 3,8 \\
\hline 28 & $0-11$ & 6,1 & 0,3 & 1,5 & 0,12 & 0,04 & 6,0 & 58,7 & 22,5 \\
\hline & $11-45$ & 6,7 & 0,4 & 0,9 & 0,06 & 0,01 & 1,0 & 57,0 & 4,6 \\
\hline 29 & $0-23$ & 7,0 & 0,0 & 9,5 & 0,38 & 0,13 & 24,0 & 48,6 & 9,3 \\
\hline & $23-46$ & 6,7 & 0,0 & 19 & 0,16 & 0,45 & 0,0 & 37,1 & 5,4 \\
\hline 30 & $0-20$ & 6,3 & 0,4 & 1,4 & 0,24 & 0,03 & 3,0 & 55,7 & 14,0 \\
\hline & $20-\overline{4} 5$ & 5,2 & 0,9 & 0,6 & 0,17 & 0,02 & 0,0 & 40,8 & 8,5 \\
\hline 31 & $0-15$ & 6,9 & 0,1 & 5,9 & 0,52 & 0,09 & 12,0 & 43,7 & 19,4 \\
\hline & $15-45$ & 5,6 & 0,1 & 3,7 & 0,16 & 0,03 & 4,0 & 36,6 & 11,6 \\
\hline 32 & $0-25$ & 5,7 & 0,0 & 19,8 & 0,35 & 0,02 & 3,0 & 35,9 & 11,6 \\
\hline & $25-65$ & 5,0 & 0,1 & 38,5 & 0,16 & 0,81 & 0,0 & 35,3 & 4,6 \\
\hline 33 & $0-8$ & 4,7 & 0,1 & 4,0 & 0,38 & 0,01 & 0,5 & 60,0 & 7,7 \\
\hline & $8-24$ & 5,0 & 0,1 & 2,2 & 0,24 & 0,01 & 0,5 & 56,6 & 4,6 \\
\hline 34 & $0-8$ & 7,2 & 0,0 & 9,4 & 0,31 & 0,03 & 11,0 & 59,0 & 14,8 \\
\hline & $8-23$ & 7,0 & 0,0 & 7,9 & 0,1 & 0,03 & 1,0 & 51 & 8,5 \\
\hline
\end{tabular}

(1) Embrapa (1997). ${ }^{(2)} \mathrm{KCl} 1 \mathrm{~mol} \mathrm{~L}^{-1}$ (Defelipo \& Ribeiro, 1997). ${ }^{(3)}$ Mehlich-1 (Defelipo \& Ribeiro, 1997). ${ }^{(4)}$ P-remanescente (Alvarez V. et al., 2000), dados compilados de Oliveira \& Nascimento (2006). 
O controle de qualidade da análise foi feito utilizando duas amostras de solos com valores certificados dos metais. Os solos certificados foram o SRM2711 Montana soil (Moderately elevated trace element concentrations) e o SRM2709 San Joaquin soil (Baseline trace element concentrations), certificados pelo National Institute of Standards and Technology (NIST). Os controles (SRM2709 e SRM2711) foram introduzidos a cada conjunto de 12 amostras analisadas e acompanharam todo o processo de digestão e dosagem dos elementos.

Os ácidos utilizados nas análises possuíam elevada pureza (Merck PA). Todas as soluções foram preparadas em água ultrapura (Sistema Direct-Q 3 Millipore). Para limpeza e descontaminação das vidrarias, elas foram mantidas em solução de ácido nítrico $5 \%$ por 24 h e enxaguadas com água destilada.

A determinação dos teores dos metais foi efetuada por espectrometria de emissão óptica (ICP-OES/ Optima 7000 Perkin Elmer) com modo de observação duplo (axial e radial) e detector de estado sólido, com sistema de introdução via amostrador automático AS 90 plus. Os parâmetros operacionais do equipamento seguiram a recomendação do fabricante. O modo de observação dos elementos pelo plasma variou de acordo com a concentração esperada nas amostras. Os de menor abundância (Zn, Ni, Cu e Co) foram determinados em vista axial atenuada, enquanto os elementos mais abundantes no solo (Fe e Mn) foram determinados na vista radial ou radial atenuada. A configuração na axial permite uma leitura com maior sensibilidade e menor limite de detecção, comparado ao modo radial. A escolha do modo de observação do equipamento foi feita de acordo com os teores médios de metais em solos encontrados na literatura e confirmada por análises-teste prévias para ajuste das leituras no aparelho.

Devido ao caráter exploratório dos dados obtidos, realizou-se estatística descritiva (média, mediana e desvio) e foram estabelecidas correlações lineares de Pearson entre metais e destes com características do solo, utilizando o programa Statistical Analyses System (SAS, 1999).

\section{RESULTADOS E DISCUSSÃO}

As amostras do NIST têm seus teores certificados determinados com base em métodos de determinação do teor total, seja por utilização de digestões contendo ácido fluorídrico (HF) para decomposição dos silicatos do solo ou mediante utilização de métodos não destrutivos, como fluorescência de raios X (NIST, 2002). As determinações dos elementos com base em digestões pseudototais, por exemplo, com utilização de $\mathrm{HNO}_{3}$ e $\mathrm{HCl}$ (método 3051A), não devem ser comparadas à dos teores certificados totais. Apesar de essa ser uma prática comum, é inadequada. O próprio NIST recomenda a comparação de métodos que não utilizam HF (3050, 3051 e suas atualizações) com as recuperações baseadas em valores lixiviados (leachable concentrations).

De modo geral, as taxas de recuperação foram muito boas para $\mathrm{Co}, \mathrm{Cu}, \mathrm{Fe}$ e $\mathrm{Mn}(80$ e $90 \%$; 88 e 103 \%; 92 e109 \%; 103 e 108 \%, para San Joaquim e Montana, respectivamente) (Quadro 3). Recuperações inferiores foram obtidas para Ni e Zn (80 e 65 \%; e 68 e $78 \%$, respectivamente), em ambos os solos certificados.

Quadro 3. Recuperação média dos metais nos solos certificados utilizados nas análises, valores certificados e recuperados por lixiviação

\begin{tabular}{|c|c|c|c|c|c|c|}
\hline Metal & $\begin{array}{l}\text { Solo } \\
\text { NIST }\end{array}$ & $\begin{array}{c}\text { Valor } \\
\text { determinado }\end{array}$ & $\begin{array}{c}\text { Valor } \\
\text { Certificado } \\
\text { (NIST) }\end{array}$ & $\begin{array}{l}\text { Recuperação } \\
\text { (determinado) }\end{array}$ & $\begin{array}{c}\text { Recuperação } \\
\text { por lixiviado } \\
\text { (NIST) }\end{array}$ & $\begin{array}{c}\text { Recuperação } \\
\text { com base no } \\
\text { lixiviado }\end{array}$ \\
\hline & & $-\mathrm{m}$ & & & $\%$ & - \\
\hline \multirow{2}{*}{ Co } & 2709 & 9,65 & $13,4 \pm 0,7$ & 72 & 90 & 80 \\
\hline & 2711 & 7,43 & 10 & 74 & 82 & 90 \\
\hline \multirow{2}{*}{$\mathrm{Cu}$} & 2709 & 28,03 & $34,6 \pm 0,7$ & 81 & 92 & 88 \\
\hline & 2711 & 103,74 & $114 \pm 2$ & 91 & 88 & 103 \\
\hline \multirow{2}{*}{$\mathrm{Fe}$} & 2709 & 27685,00 & $35000 \pm 1100$ & 79 & 86 & 92 \\
\hline & 2711 & 23900,30 & $28900 \pm 600$ & 83 & 76 & 109 \\
\hline \multirow{2}{*}{$\mathrm{Mn}$} & 2709 & 486,35 & $538 \pm 17$ & 90 & 87 & 103 \\
\hline & 2711 & 526,99 & $638 \pm 28$ & 83 & 77 & 108 \\
\hline \multirow{2}{*}{$\mathrm{Ni}$} & 2709 & 62,39 & $88 \pm 5$ & 71 & 89 & 80 \\
\hline & 2711 & 10,55 & $20,6 \pm 1,1$ & 51 & 78 & 65 \\
\hline \multirow{2}{*}{$\mathrm{Zn}$} & 2709 & 67,95 & $106 \pm 3$ & 64 & 94 & 68 \\
\hline & 2711 & 240,37 & $350,4 \pm 4,8$ & 69 & 89 & 78 \\
\hline
\end{tabular}

NIST: National Institute of Standards and Technology. 
Os teores de $\mathrm{Cu}$, Ni e Co nos solos (Quadro 4) foram considerados baixos em comparação aos de solos de outras regiões do País. Por exemplo, Campos et al. (2003), analisando 19 Latossolos de diferentes regiões do País e desenvolvidos a partir de vários materiais de origem, observaram teores de $\mathrm{Cu}$ variando entre 3 e $238 \mathrm{mg} \mathrm{kg}^{-1}$, e de Ni variando entre 3 e $45 \mathrm{mg} \mathrm{kg}^{-1}$, e os maiores teores de metais foram observados nos solos derivados de rochas máficas. Considerando os resultados em todos os horizontes, cerca de $50 \%$ dos

Quadro 4. Teores totais de Cu, Ni e Co nos horizontes superficiais (sup.) e subsuperficiais (sub.) dos solos de referência de Pernambuco

\begin{tabular}{|c|c|c|c|c|c|c|}
\hline \multirow{2}{*}{ Perfil } & \multicolumn{2}{|c|}{$\mathrm{Cu}$} & \multicolumn{2}{|c|}{$\mathrm{Ni}$} & \multicolumn{2}{|c|}{ Co } \\
\hline & Sup & Sub & Sup & Sub & Sup & Sub \\
\hline & \multicolumn{6}{|c|}{$\mathrm{mg} \mathrm{kg}^{-1}$} \\
\hline & \multicolumn{6}{|c|}{ Zona da Mata } \\
\hline 1 & 0,92 & 0,85 & 4,40 & 5,80 & 1,096 & 0,938 \\
\hline 2 & $<\mathrm{Ld}$ & 0,10 & 3,00 & 1,38 & 0,555 & 0,130 \\
\hline 3 & 0,18 & 0,48 & 0,98 & 0,68 & 0,269 & 0,070 \\
\hline 4 & 1,88 & 2,18 & $<\mathrm{Ld}$ & 0,63 & 0,423 & 0,217 \\
\hline 5 & 0,60 & 0,35 & $<\mathrm{Ld}$ & $<\mathrm{Ld}$ & 2,882 & 3,611 \\
\hline 6 & 1,40 & 1,80 & 2,38 & 2,23 & 1,132 & 0,714 \\
\hline 7 & 23,93 & 20,78 & 17,13 & 14,60 & 8,975 & 7,802 \\
\hline 8 & 18,03 & 12,83 & 11,10 & 14,00 & 2,314 & 2,810 \\
\hline 9 & 0,95 & 1,23 & 0,75 & 1,33 & 0,493 & 0,422 \\
\hline 10 & 4,45 & 4,68 & 2,25 & 2,18 & 0,480 & 0,151 \\
\hline 11 & 27,90 & 27,80 & 18,15 & 15,10 & 5,578 & 2,633 \\
\hline 12 & 26,05 & 25,48 & 11,85 & 13,73 & 6,476 & 6,617 \\
\hline \multirow[t]{2}{*}{ Média } & 8,86 & 8,21 & 6,00 & 5,97 & 2,56 & 2,18 \\
\hline & \multicolumn{6}{|c|}{ Agreste } \\
\hline 13 & 0,70 & 0,48 & 0,13 & 0,23 & $<\mathrm{Ld}$ & 0,045 \\
\hline 14 & 1,80 & 1,55 & 0,10 & 0,25 & 0,012 & 0,251 \\
\hline 15 & 3,90 & 3,43 & 7,60 & 7,48 & 1,779 & 1,698 \\
\hline 16 & 2,48 & 0,63 & 0,15 & $<\mathrm{Ld}$ & 2,467 & 1,913 \\
\hline 17 & 0,50 & 0,20 & $<\mathrm{Ld}$ & 0,05 & 0,996 & 1,291 \\
\hline 18 & 6,08 & 2,93 & 6,48 & 2,68 & 3,305 & 1,658 \\
\hline 19 & 2,95 & 2,70 & 1,83 & 1,88 & 3,527 & 5,395 \\
\hline 20 & 0,70 & 0,38 & 0,55 & 0,53 & 0,808 & 1,020 \\
\hline 21 & 1,60 & 1,50 & 0,58 & 0,80 & 0,073 & 0,476 \\
\hline 22 & 2,03 & 1,30 & 1,58 & 0,98 & 0,283 & 0,592 \\
\hline $22 \mathrm{~A}$ & 10,20 & 10,18 & 37,45 & 44,35 & 7,637 & 8,500 \\
\hline \multirow[t]{2}{*}{ Média } & 2,99 & 2,30 & 5,13 & 5,38 & 1,90 & 2,08 \\
\hline & \multicolumn{6}{|c|}{ Sertão } \\
\hline 23 & 3,18 & 2,90 & 0,95 & 1,10 & 1,371 & 1,091 \\
\hline 24 & 2,88 & 4,43 & 1,15 & 1,85 & 1,684 & 2,125 \\
\hline 25 & 0,50 & 1,28 & $<\mathrm{Ld}$ & 0,08 & 0,044 & 0,109 \\
\hline 26 & 14,73 & 24,63 & 13,63 & 21,38 & 12,457 & 15,535 \\
\hline 27 & 10,78 & 10,83 & 8,83 & 9,78 & 7,440 & 7,372 \\
\hline 28 & 0,45 & 0,88 & $<\mathrm{Ld}$ & $<\mathrm{Ld}$ & 0,131 & 0,003 \\
\hline 29 & 6,03 & 7,00 & 5,35 & 5,20 & 7,122 & 7,410 \\
\hline 30 & 2,03 & 3,40 & 1,28 & 1,10 & 2,571 & 2,789 \\
\hline 31 & 14,80 & 17,23 & 11,73 & 11,75 & 7,942 & 8,252 \\
\hline 32 & 26,35 & 34,73 & 20,63 & 16,48 & 15,667 & 7,640 \\
\hline 33 & 2,65 & 5,28 & 1,28 & 2,78 & 1,454 & 2,306 \\
\hline 34 & 26,58 & 28,68 & 16,60 & 33,35 & 14,385 & 14,522 \\
\hline Média & 9,25 & 11,77 & 6,79 & 8,74 & 6,02 & 5,76 \\
\hline Mediana & 3,06 & 3,41 & 2,04 & 2,20 & 2,05 & 2,02 \\
\hline Média & 7,15 & 7,57 & 6,00 & 6,74 & 3,54 & 3,37 \\
\hline Desvio & 8,94 & 9,78 & 8,13 & 9,91 & 4,19 & 3,99 \\
\hline
\end{tabular}

Ld: Limite de detecção. teores de $\mathrm{Cu}, 60 \%$ dos teores de $\mathrm{Ni}$ e $65 \%$ dos teores de Co tiveram valores inferiores a $3 \mathrm{mg} \mathrm{kg}^{-1}$.

No entanto, os teores situaram-se em uma ampla faixa de variação: $0,10-34,73 \mathrm{mg} \mathrm{kg}^{-1}$ para o $\mathrm{Cu}, 0,05$ $44,35 \mathrm{mg} \mathrm{kg}^{-1}$ para o Ni e $0,07-15,66 \mathrm{mg} \mathrm{kg}^{-1}$ para o Co, não sendo observadas variações significativas entre os horizontes de um mesmo perfil. Esses resultados refletem o pequeno teor desses metais nos materiais de origem dos solos de Pernambuco, compostos, predominantemente, por rochas metamórficas e sedimentares e sedimentos do Terciário (Ribeiro et al., 1999), e corroboram a necessidade de estudos regionalizados para determinação dos valores naturais desses metais em solos. Por exemplo, a utilização de valores referência de teor baseado em dados de uma região com solos derivados de material de origem mais máfico poderia mascarar o início de um processo de contaminação.

Os teores mais altos de $\mathrm{Cu}, \mathrm{Ni}$ e $\mathrm{Co}$ foram observados nos perfis de Nitossolo, Argissolo, Organossolo e Gleissolo da Zona da Mata (perfis 7, 8, 11 e 12) e em perfis de Neossolos Litólico, Neossolo Flúvico, Cambissolo e Vertissolo (perfis 22A, 26, 27, 31, 32 e 34) das regiões do Agreste e Sertão (Quadro 4), indicando a tendência de manutenção desses metais, na Zona da Mata, em solos localizados em ambientes mais conservadores, como as várzeas, para os quais são transferidos elementos lixiviados de solos localizados em cotas superiores, do entorno, e conservam-nos durante o tempo de formação. Isso resulta em teores mais elevados que os demais solos da região, formados por material de origem extremamente pobre nesses elementos (perfis 11 e 12). Exceção é feita ao Nitossolo (perfil 7), cujo teor mais elevado está associado a material de origem mais rico, devido a uma ocorrência geológica, de pequena extensão, com presença de basalto em sua formação.

Os outros perfis que se destacam, pelos teores mais elevados de $\mathrm{Cu}$, Ni e Co, são os solos menos intemperizados na região fisiográfica do Sertão (perfis 26, 27, 31, 32 e 34). Contudo, esses valores são menores que os apresentados por Caires (2009) para solos de Minas Gerais, onde os maiores teores de $\mathrm{Cu}, \mathrm{Ni}$ e Co foram observados na ordem dos Latossolos, com médias de 74,70; 46,65 e 23,5 mg kg-1, respectivamente. Essa diferenciação pode ser entendida pela composição do material de origem dos Latossolos de Pernambuco, associados, em sua maioria, a sedimentos arenoargilosos, com menor potencial de liberação desses metais para o sistema. Esses solos, com fração argila predominantemente caulinítica e menores concentrações de óxidos de Fe e Mn do que os solos de Minas Gerais, têm menor capacidade de reduzir a mobilidade dos metais pesados, mediante processos de sorção. Devido a isso, os já baixos teores desses metais podem ser mais facilmente perdidos do sistema.

As estreitas correlações ( $r>70$ \%, Quadro 5), estabelecidas entre os teores de $\mathrm{Cu}, \mathrm{Ni}$ e Co sugerem uma associação comum ao material de origem, uma 
vez que esses metais ocorrem conjuntamente, como elementos acessórios, na composição da biotita (Alloway, 1990), mineral presente na maioria dos perfis analisados. Esses resultados corroboram o baixo potencial, da maioria dos solos do Estado, em contribuir com o suprimento de $\mathrm{Cu}$ às plantas (Nascimento et al., 2006).

Os valores de $\mathrm{Zn}$ foram maiores, em média, para os solos da Zona da Mata, com 30,7 e 22,5 mg kg-1 (Quadro 6), para horizontes superficiais e subsuperficiais, respectivamente, seguidos pelo Sertão, com valores de 19,61 e 21,00 mg kg-1, e Agreste, com 16,70 e $11,93 \mathrm{mg} \mathrm{kg}^{-1}$. Oliveira \& Costa (2004), analisando metais pesados em uma topossequência na região do Triângulo Mineiro, encontraram valores semelhantes para solos originados de gnaisse, arenito e sedimentos e superiores em solos derivados de basalto.

As correlações significativas (Quadro 5) estabelecidas entre os teores de Zn e argila, nos dois horizontes $(0,65$ e 0,74$)$, são indicativas dos baixos teores desse metal em solos de textura arenosa - por exemplo: o Espodossolo (perfil 3), com 828 e $811 \mathrm{~g} \mathrm{~kg}^{-1}$ de areia nos horizontes superficial $\left(5,25 \mathrm{mg} \mathrm{kg}^{-1}\right) \mathrm{e}$ subsuperficial (1,38 $\left.\mathrm{mg} \mathrm{kg}^{-1}\right)$, respectivamente, e o Neossolo Quartzarênico (perfil 25) e o Argissolo Amarelo (perfil 33), com teores de areia de 904 e $837 \mathrm{~g} \mathrm{~kg}^{-1}$, em superfície , e 911 e $782 \mathrm{~g} \mathrm{~kg}^{-1}$, em subsuperfície, com teores de Zn de 2,38; 4,55; e 1,05; $7,83 \mathrm{mg} \mathrm{kg}^{-1}$, respectivamente. Todos os solos encontram-se muito abaixo do Valor de Prevenção

Quadro 5. Coeficientes de correlação linear de Pearson (r) entre teores de metais e propriedades dos solos nos horizontes superficiais e subsuperficiais dos solos de referência de Pernambuco

\begin{tabular}{|c|c|c|c|c|c|c|}
\hline & $\mathrm{Ni}$ & $\mathbf{C u}$ & $\mathbf{F e}$ & Mn & $\mathrm{Zn}$ & Co \\
\hline \multicolumn{7}{|c|}{ Horizonte superficial } \\
\hline $\mathrm{Cu}$ & $0,73^{* * *}$ & & & & & \\
\hline $\mathrm{Fe}$ & $0,43^{* * *}$ & $0,58^{* * *}$ & & & & \\
\hline $\mathrm{Mn}$ & $0,64^{* * *}$ & $0,61^{* * *}$ & $0,61 * * *$ & & & \\
\hline $\mathrm{Zn}$ & $0,61^{* * *}$ & $0,78^{* * *}$ & $0,55^{* * *}$ & $0,50 * * *$ & & \\
\hline Co & $0,72^{* * *}$ & $0,81^{* * *}$ & $0,57^{* * *}$ & $0,79 * * *$ & $0,60^{* * *}$ & \\
\hline $\mathrm{pH}$ & $0,36^{* * *}$ & $0,21^{*}$ & $0,05^{\mathrm{ns}}$ & $0,56^{* * *}$ & $0,04^{\mathrm{ns}}$ & $0,52^{* * *}$ \\
\hline Arg & $0,36 * * *$ & $0,63^{* * *}$ & $0,75^{* * *}$ & $0,43^{* * *}$ & $0,65^{* * *}$ & $0,46^{* * *}$ \\
\hline MO & $0,29 * *$ & $0,47 * * *$ & $0,02^{\mathrm{ns}}$ & $-0,07^{\mathrm{ns}}$ & $0,55^{* * *}$ & $0,09^{\mathrm{ns}}$ \\
\hline \multicolumn{7}{|c|}{ Horizonte subsuperficial } \\
\hline $\mathrm{Cu}$ & $0,71^{* * *}$ & & & & & \\
\hline $\mathrm{Fe}$ & $0,51 * * *$ & $0,67 * * *$ & & & & \\
\hline $\mathrm{Mn}$ & $0,64^{* * *}$ & $0,57 * * *$ & $0,59 * * *$ & & & \\
\hline $\mathrm{Zn}$ & $0,62^{* * *}$ & $0,81^{* * *}$ & $0,74^{* * *}$ & $0,66^{* * *}$ & & \\
\hline Co & $0,77^{* * *}$ & $0,76^{* * *}$ & $0,65^{* * *}$ & $0,92^{* * *}$ & $0,77 * * *$ & \\
\hline $\mathrm{pH}$ & $0,45^{* * *}$ & $0,20 *$ & $0,03^{\text {ns }}$ & $0,57^{* * *}$ & 0,24 & $0,58^{* * *}$ \\
\hline Arg & $0,26^{* *}$ & $0,55^{* * *}$ & $0,77 * * *$ & $0,35^{* * *}$ & $0,74 * * *$ & $0,44^{* * *}$ \\
\hline MO & $-0,03^{\mathrm{ns}}$ & $0,16^{\mathrm{ns}}$ & $0,18^{\text {ns }}$ & $-0,15^{\mathrm{ns}}$ & $-0,06^{\mathrm{ns}}$ & $-0,04^{\mathrm{ns}}$ \\
\hline
\end{tabular}

***, ${ }^{\circ} \mathrm{e}^{\mathrm{ns}}:$ significativos a $5,<1,<0,1 \%$ e não significativo, respectivamente. indicado pelo CONAMA (300 $\mathrm{mg} \mathrm{kg}^{-1}$ ), apenas os perfis de Nitossolo, Organossolo e Gleissolo da Zona da Mata possuem valores próximos ao de Valor de Referência de Qualidade da CETESB (2005), de 60 mg kg-1.

$\mathrm{O}$ conhecimento dos teores naturais de $\mathrm{Mn}$ e Fe em solos, apesar de esses elementos não serem diretamente referenciados em legislações ambientais, é importante, pois, além de serem micronutrientes vegetais, a presença destes como constituintes principais de rochas faz com que tenham importância em estudos de geoquímica, inclusive indicando, indiretamente, os teores de outros metais pesados.

Cerca de $70 \%$ dos horizontes tiveram teores inferiores a $200 \mathrm{mg} \mathrm{kg}^{-1}$ de Mn (Quadro 6). Esses valores são baixos quando comparados aos reportados por outros pesquisadores brasileiros, para os quais são comuns valores superiores em grande parte dos solos (Caires, 2009; Hadlich et al., 2007). A maior abundância de Mn em solos está associada à presença de rochas máficas na litologia da região. Entretanto, também foram constatados perfis dos solos de referência com valores situados entre 311,28 e $609,58 \mathrm{mg} \mathrm{kg}^{-1}$ de Mn (Nitossolo Vermelho, Neossolos Litólicos, Neossolo Flúvico, Cambissolo Háplico e Vertissolo Cromado), condicionados a ambiente de intemperismo menos intenso e material de origem mais rico que o dos demais solos do Estado - condições que possibilitam maior concentração e manutenção do Mn no sistema solo.

Burt et al. (2003), comparando teores de Mn em solos com e sem atividade antrópica, constataram não haver diferença no teor desse elemento em função da atividade humana, considerando esse fato um reflexo da relativa abundância e intensa dinâmica do Mn, que possui diversos estados de oxidação no solo e cuja especiação é dependente do $\mathrm{pH}$ e potencial de oxirredução. Essas considerações podem ser estendidas para o Fe, devido às similaridades entre esses elementos. Esse fato pode explicar a inexistência de valores orientadores desses metais em solos definidos por órgãos ambientais.

Nos solos da Zona da Mata foram observados os teores mais elevados de Fe, em horizontes superficiais (21,42 $\mathrm{g} \mathrm{kg}^{-1}$ ) (Quadro 6). Esse acúmulo resulta da formação de óxidos em maiores teores nessa região de intemperismo mais intenso que o das outras regiões de Pernambuco.

Esses valores foram seguidos pelos teores de Fe no Sertão (15,60 $\mathrm{g} \mathrm{kg}^{-1}$ ) e no Agreste (10,81 g kg-1). Nos horizontes subsuperficiais encontraram-se teores mais elevados que em superfície, com médias de 38,73, 18,36 e 11,25 $\mathrm{g} \mathrm{kg}^{-1}$ para as regiões de Zona da Mata, Agreste e Sertão, respectivamente. Exceções, em sua maioria, refletiram a existência de horizonte subsuperficial (AE e E) caracterizado por processos de perda de argila (perfis 2, 3, 10 e 18). Esses teores são bem menores que os relatados por outros pesquisadores que analisaram solos associados a rochas máficas e ultramáficas (Burak, 2008; Caires, 2009). 
Quadro 6. Teores totais de Fe, Mn e Zn nos horizontes superficiais (sup.) e subsuperficiais (sub.) dos solos de referência de Pernambuco

\begin{tabular}{|c|c|c|c|c|c|c|}
\hline \multirow{2}{*}{ Perfil } & \multicolumn{2}{|c|}{$\mathrm{Fe}$} & \multicolumn{2}{|c|}{ Mn } & \multicolumn{2}{|c|}{$\mathrm{Zn}$} \\
\hline & Sup & Sub & Sup & Sub & Sup & Sub \\
\hline & \multicolumn{2}{|c|}{$\mathrm{g} \mathrm{kg}^{-1}$} & & \multirow{2}{*}{\multicolumn{2}{|c|}{$\mathrm{mg} \mathrm{kg}^{-1}$}} & 5 \\
\hline & & & Zona da Mat & & & \\
\hline 1 & 17,69 & 24,03 & 45,40 & 45,05 & 33,15 & 18,63 \\
\hline 2 & 5,34 & 2,43 & 16,48 & 11,13 & 40,78 & 4,75 \\
\hline 3 & 0,94 & 0,70 & 9,85 & 9,10 & 5,25 & 1,38 \\
\hline 4 & 14,00 & 14,82 & 11,95 & 10,25 & 9,13 & 9,58 \\
\hline 5 & 16,92 & 19,92 & 140,20 & 158,98 & 23,10 & 29,18 \\
\hline 6 & 45,87 & 36,98 & 51,10 & 67,45 & 11,80 & 11,38 \\
\hline 7 & 94,50 & 48,68 & 509,05 & 393,03 & 60,98 & 53,53 \\
\hline 8 & 20,70 & 30,59 & 186,10 & 125,45 & 38,95 & 35,98 \\
\hline 9 & 4,00 & 6,37 & 43,73 & 52,85 & 7,35 & 4,08 \\
\hline 10 & 3,64 & 3,76 & 73,65 & 76,95 & 14,35 & 9,98 \\
\hline 11 & 11,52 & 13,16 & 60,20 & 20,75 & 64,85 & 27,55 \\
\hline 12 & 21,96 & 22,79 & 242,50 & 201,65 & 59,45 & 64,08 \\
\hline \multirow[t]{2}{*}{ Média } & 21,42 & 38,73 & 115,85 & 97,72 & 30,76 & 22,51 \\
\hline & & & Agreste & & & \\
\hline 13 & 1,60 & 1,46 & 26,63 & 16,45 & 8,98 & 3,23 \\
\hline 14 & 3,22 & 4,15 & 54,48 & 41,30 & 10,40 & 9,13 \\
\hline 15 & 7,15 & 7,06 & 57,33 & 34,03 & 11,25 & 8,88 \\
\hline 16 & 20,66 & 22,02 & 252,10 & 147,48 & 46,30 & 31,58 \\
\hline 17 & 7,00 & 8,34 & 97,50 & 101,33 & 12,68 & 11,95 \\
\hline 18 & 11,132 & 6,42 & 172,73 & 98,70 & 14,48 & 7,23 \\
\hline 19 & 10,41 & 14,54 & 264,03 & 291,98 & 16,53 & 16,93 \\
\hline 20 & 24,32 & 24,52 & 46,18 & 37,88 & 10,10 & 7,88 \\
\hline 21 & 1,89 & 2,91 & 22,25 & 19,08 & 7,48 & 3,63 \\
\hline 22 & 16,71 & 17,28 & 30,15 & 27,08 & 11,45 & 7,58 \\
\hline $22 \mathrm{~A}$ & 14,84 & 15,02 & 324,53 & 293,75 & 34,05 & 23,23 \\
\hline \multirow[t]{2}{*}{ Média } & 10,81 & 11,25 & 122,54 & 100,82 & 16,70 & 11,93 \\
\hline & & & Sertão & & & \\
\hline 23 & 5,31 & 4,82 & 101,35 & 55,83 & 11,05 & 7,48 \\
\hline 24 & 4,41 & 5,36 & 74,33 & 89,05 & 9,55 & 12,15 \\
\hline 25 & 0,84 & 1,16 & $<\mathrm{Ld}$ & $<\mathrm{Ld}$ & 2,38 & 1,05 \\
\hline 26 & 23,36 & 29,06 & 530,75 & 619,50 & 34,98 & 56,30 \\
\hline 27 & 14,96 & 15,00 & 283,93 & 271,88 & 24,88 & 25,08 \\
\hline 28 & 0,91 & 0,88 & 18,35 & $<\mathrm{Ld}$ & 9,28 & 5,63 \\
\hline 29 & 16,15 & 18,62 & 291,83 & 268,18 & 16,68 & 14,98 \\
\hline 30 & 6,05 & 11,02 & 240,10 & 108,48 & 9,58 & 11,65 \\
\hline 31 & 34,34 & 38,15 & 497,45 & 504,00 & 24,55 & 22,13 \\
\hline 32 & 36,48 & 48,08 & 327,35 & 47,83 & 42,00 & 43,23 \\
\hline 33 & 4,95 & 6,07 & 29,40 & 47,55 & 4,55 & 7,83 \\
\hline 34 & 39,48 & 42,13 & 311,28 & 595,25 & 45,88 & 44,53 \\
\hline Média & 15,60 & 18,36 & 225,51 & 217,30 & 19,61 & 21,00 \\
\hline Mediana & 11,52 & 14,54 & 99,42 & 83,00 & 14,35 & 11,80 \\
\hline Media & 16,09 & 16,24 & 155,55 & 139,69 & 22,52 & 18,67 \\
\hline Desvio & 17,68 & 13,70 & 151,52 & 165,05 & 17,40 & 16,48 \\
\hline
\end{tabular}

$<\mathrm{Ld}$ : menor que o limite de deteç̧ão para $\mathrm{Mn}\left(0,1 \mu \mathrm{g} \mathrm{kg}{ }^{-1}\right)$.

O Nitossolo Vermelho (perfil 7) é o solo com maior teor de Fe em ambos os horizontes (94,50 e 48,68 $\mathrm{g} \mathrm{kg}^{-1}$ ), devido à presença de basalto na composição do material de origem; contudo, provavelmente por este ocorrer em associação com traquito, rocha ácida com menor teor de $\mathrm{Fe}$, o teor deste metal no perfil é inferior ao observado em solos derivados de basalto em Minas
Gerais, que apresentaram valores situados entre 250 e $300 \mathrm{~g} \mathrm{~kg}^{-1}$ (Caires, 2009). Saldanha et al. (1997), analisando 15 perfis de solo distribuídos por diversas regiões do Brasil, observaram teores médios variando entre 5,6 e 138,5 $\mathrm{g} \mathrm{kg}^{-1}$. Burt et al. (2003) reportaram grande amplitude de $\mathrm{Fe}$ em solos de referência coletados em toda a extensão territorial dos EUA, com 
valores situados entre 0,003 e $227 \mathrm{~g} \mathrm{~kg}^{-1}$. Essa grande diferença reflete a diversidade de materiais de origem que compõem esses solos.

Correlações significativas foram estabelecidas entre os teores de Fe e argila em ambos os horizontes $(r$ $=0,75$ e $r=0,77)$, pelo fato de grande parte do elemento encontrar-se concentrada em argilominerais e óxidos de Fe que compõem essa fração. O teor de argila foi a característica que melhor se correlacionou com os demais metais em ambos os horizontes. Esse fato deve-se à íntima relação dessa fração, seja contribuindo para a liberação de metais no sistema solo ou pela afinidade com alguns metais em processos de sorção, que limitam a mobilidade destes no sistema.

O teor de matéria orgânica, no horizonte superficial, correlacionou-se positivamente $(\mathrm{p}<0,001)$ com os teores de $\mathrm{Zn}(\mathrm{r}=0,55)$ e $\mathrm{Cu}(\mathrm{r}=0,47)$, tendência explicada pela afinidade desses elementos com a fração matéria orgânica do solo (Nascimento et al., 2002; Melo et al., 2008; Silva \& Vitti, 2008). Essa tendência corrobora o observado por Araújo \& Nascimento (2005) em extrações sequenciais, que obtiveram os maiores teores de $\mathrm{Zn}$ associado às frações orgânicas e residuais. A ausência de correlação do teor de matéria orgânica com Fe, Mn e Co ocorre, provavelmente, devido ao fato de os teores totais desses elementos, em solos não contaminados, estarem mais associados a frações minerais, como pode ser observado pela correlação significativa entre esses elementos e o teor de argila dos solos.

\section{CONCLUSÕES}

1. Correlações significativas foram estabelecidas entre os metais e destes com a fração argila do solo, em ambos os horizontes, indicando a associação comum da maioria dos metais a solos mais argilosos.

2. A maioria dos solos apresentou teores de Fe, Mn, $\mathrm{Zn}, \mathrm{Cu}, \mathrm{Ni}$ e Co menores que os de outras regiões do País, com litologia mais máfica, o que corrobora o fato de que os teores desses elementos são mais diretamente relacionados aos minerais ferromagnesianos.

3. Os resultados indicam baixo potencial dos solos de Pernambuco em suprir $\mathrm{Cu}$, Co e Ni para plantas, enquanto deficiências de $\mathrm{Zn}$, Fe e Mn são menos prováveis.

4. Os teores naturais de Fe, Mn, Zn, Cu, Ni e Co determinados podem ser utilizados como base para definição dos Valores Referência de Qualidade para os solos de Pernambuco, de acordo com o preconizado pela legislação nacional.

\section{AGRADECIMENTOS}

A primeira autora agradece à Capes/Facepe e ao Programa de Pós-Graduação em Ciência do Solo da
UFRPE a concessão da bolsa de estudos durante o doutoramento e parte do financiamento deste trabalho.

Os autores agradecem o $\mathrm{CNPq}$ pelo financiamento (Processo 472482/2006-8).

\section{LITERATURA CITADA}

ALLOWAY, B.J. Heavy metals in soils. New York, John Wiley \& Sons, 1990. 39p.

ALVAREZ V., V.H.; NOVAIS, R.F.; DIAS, L.E. \& OLIVEIRA, J.A. Determinação e uso do fósforo remanescente. Viçosa, MG, Sociedade Brasileira de Ciência do Solo, 2000. 32p. (Boletim Informativo, 25)

ARAÚJO, J.C.T. \& NASCIMENTO, C.W.A. Fracionamento e disponibilidade de zinco por diferentes extratores em solos incubados com lodo de esgoto. R. Bras. Ci. Solo, 29:977985,2005

BAIZE, D. \& STERCKEMAN, T. Of the necessity of knowledge of the natural pedo-geochemical background content in the evaluation of the contamination of soils by trace elements. Sci. Total Environ., 264:127-139, 2001.

BURAK, D.L. Geoquímica e distribuição de metais pesados em solos na Região de Unaí, Paracatu e Vazante, MG. Viçosa, MG, Universidade Federal de Viçosa, 2008, 173p. (Tese de Doutorado)

BURT, R.; WILSON, M.A.; MAYS, M.D. \& LEE, C.W. Major and trace elements of selected pedons in the USA. J. Environ. Qual., 32:2109-2121, 2003.

CAIRES, S.M. Determinação dos teores naturais de metais pesados em solos do Estado de Minas Gerais como subsídio ao estabelecimento de Valores de Referência de Qualidade. Viçosa, MG, Universidade Federal de Viçosa, 2009. 304p. (Tese de Doutorado)

CAMPOS, M.L.; PIERANGELI, M.A.P.; GUILHERME, L.R.G.; MARQUES, J.J. \& CURI, N. Baseline concentration of heavy metals in Brazilian Latosols. Comm. Soil Sci. Plant. Anal., 34:547-557, 2003.

CETESB - Companhia de tecnologia de saneamento ambiental. 2005. Decisão da Diretoria. Valores orientadores para solos e águas subterrâneas do estado de São Paulo. 195:1-4, 2005 .

CONSELHO NACIONAL DO MEIO AMBIENTE - CONAMA. Resolução no 420, de 28 de dezembro de 2009. "Dispõe sobre critérios e valores orientadores de qualidade do solo quanto à presença de substâncias químicas e estabelece diretrizes para o gerenciamento ambiental de áreas contaminadas por essas substâncias em decorrência de atividades antrópicas.", Diário Oficial [da República Federativa do Brasil], Brasília, DF, no 249, de 30/12/2009. p.81-84. Disponível em <http://www.mma.gov.br/port/ conama/legiano1>. Acesso em 13 jan. 2010.

DEFELIPO, B.V. \& RIBEIRO, A.C. Análise química do solo, metodologia. 2.ed. Viçosa, MG, Universidade Federal de Viçosa, 1997. 26p. 
EMPRESA BRASILEIRA DE PESQUISA AGROPECUÁRIA . EMBRAPA. Manual de métodos de análise de solo. 2.ed. Rio de Janeiro, Centro Nacional de Pesquisa de Solos, 1997. $212 \mathrm{p}$

HADLICH, G.M.; CELINO, J.J.; UCHA, J.M. \& SANTIAGO J.S. Geoquímica de metais traços em Apicuns (Planícies Hipersalinas) do campo de produção de petróleo Dom João, São Francisco do Conde, Bahia.. In: CONGRESSO BRASILEIRO DE GEOQUÍMICA, 11., Atibaia, 2007. Anais... Atibaia, Sociedade Brasileira de Geoquímica, 2007. CD ROM.

MELO, E.E.C.; NASCIMENTO, C.W.A.; SANTOS, A.C.Q. \& SILVA, A.S. Disponibilidade e fracionamento de $\mathrm{Cd}, \mathrm{Pb}$, $\mathrm{Cu}$ e $\mathrm{Zn}$ em função do $\mathrm{pH}$ e tempo de incubação com o solo. Ci. Agrotec., 32:776-784, 2008.

NASCIMENTO, C.W.A.; FONTES, R.L.F.; NEVES, J.C.L. \& MELÍCIO, A.C.F.D. Fracionamento, dessorção e extração química de zinco em Latossolos. R. Bras. Ci. Solo, 26:599. 606, 2002.

NASCIMENTO, C.W.A.; OLIVEIRA, A.B.; RIBEIRO, M.R. \& MELO, E.E.C. Distribution and Availability of zinc and copper in benchmark soils of Pernambuco State, Brazil. Comm. Soil Sci. Plant Anal., 37:109-125, 2006.

NATIONAL INSTITUTE OF STANDARDS AND TECHNOLOGY - NIST. Standard Reference Materials SRM 2709, 2710 and 2711Addendum Issue Date: 18 January 2002. Disponível em : < http://ts.nist.gov/ MeasurementServices/ReferenceMaterials/ archived_certificates>. Acesso em 10 out 2009.

OLIVEIRA, A.B. \& NASCIMENTO, C.W.A. Formas de manganês e ferro em solos de referência de Pernambuco. R. Bras. Ci. Solo, 30:99-110, 2006.
OLIVEIRA, T.S. \& COSTA, L.M. Metais pesados em solos de uma topolitossequencia do Triângulo Mineiro. R. Bras. Ci. Solo, 28:785-796, 2004.

RIBEIRO, M.R.; JACOMINE, P.K.T. \& LIMA, J.F.W.F. Caracterização e classificação de solos de referência do Estado de Pernambuco. Recife, Universidade Federal Rural de Pernambuco, 1999. 140p.

SAS INSTITUTE. Statistical analysis system. Procedure guide for personal computer. Cary, 1999.

SALDANHA, M.F.C.; PÉREZ, D.V.; MENEGUELLI, N.A.; MOREIRA, J.C. \& VAITSMAN, D.S. Avaliação de cinco tipos de abertura para determinação dos teores de ferro, manganês e zinco em alguns solos brasileiros. 1997. (Pesquisa em andamento Embrapa-CNPS, 1) Disponível em: <www. cnps.embrapa.br/solosbr/pdfs/ pesquisaand_011997.pdf >. Acessado em: 10 Jan 2010

SILVA, M.L.S. \& VITTI, G.C. Fracionamento de metais pesados em solo contaminado antes e após cultivo de arroz. Quimica Nova, 31:1385-1391, 2008.

UNITED STATES DEPARTMENT OF AGRICULTURE USDA. Disponível em: <www.soils.usda.gov/technical/ handbook/contents/part630.html>. (Acesso em Jan. 2010)

UNITED STATES ENVIRONMENTAL PROTECTION AGENCY - USEPA. Method 3051a - Microwave assisted acid digestion of sediments, sludges, soils, and oils. 1998. Revision 1 Fev 2007. 30p. Disponível em: 〈http:// www.epa.gov/epawaste/hazard/testmethods/sw846/pdfs/ 3051a.pdf. Acesso em 14 fev 2010. 